\title{
Gender based way in initial pre-professional training system of young football players.
}

\author{
Anatoly Suchilin ${ }^{1 *}$, Viktor Yakimovich ${ }^{1}$, Lyudmila Stolyarchuk ${ }^{2}$ \\ ${ }^{1}$ Volgograd State Academy of Physical Culture, 400005, Volgograd, Russia \\ ${ }^{2}$ Volgograd State Social and Pedagogical University, 400066, Volgograd, Russia
}

\begin{abstract}
The paper considers the gender-based way in initial pre-professional training of young football players (boys and girls) during their training in children's and youth sport schools. The gender-based way and system analysis using allows us to get a handle on a system of initial training that includes a number of subsystems. All of them have a goal, objectives, program material and technology (methodology) for its implementation. Unlike the well-known studies, this one consists of using the same methodology in initial preprofessional training for joint football classes of boys and girls in age from 6 to 12 years old. This does not contradict their age characteristics and contributes to mutual enrichment in the development of technical and tactical techniques. From the age of 13, boys and girls begin to choose groups and football teams for in-depth pre-professional training to professional men's and women's football.
\end{abstract}

\section{Introduction}

The Russian football transition to professional level requires a revision of the football reserve training traditional system. It for many years has been refilled ("fed", filled, formed) from the children's and youth sports schools' fundamental basis. For decades boys initial training was carried out in groups of initial training at 10, later at 8 years old, where the beginning players, who learnt the game of football on yard areas were selected. The researchers justly wrote about this: "children already at the age of 8-9 years play football on their own" [1, p. 3]. In other words, in Soviet times, a well-developed mass football for boys in the community worked for children's and youth schools. At the same time, women's football was ignored, since girls were not accepted into sports sections; state educational programs were developed only for boys" [2,3].

The new economic and social policy is currently accompanied by a reduction in mass sports, including football, both locally and in children's and youth sports schools. The phrase "providing paid educational services" has become popular. At the same time, higher requirements were imposed on graduates of sports children's and youth schools of the Olympic reserve and sports training centers. Today, they must be competitive in the sports market. It means in the labor market. This requires changes in educational process, increase the value of the initial preprofessional training for professional football, taking into account the current situation, to update the revision of the traditional sports training system and creation of necessary prerequisites for both boys and girls to further enhance the status of professional footballer. Democratic transformations in Russia open up wide opportunities for this. In accordance with modern normative framework, sports institution can be created by the founders on their own initiative and contribute to achieving a level of success commensurate with the abilities of students [4, p. 94-95], regardless of the sex of young players.

High-speed globalization in the modern world leads to the transformation of gender relations in all spheres of society, including sports, counting football, and directly affects the reserve initial pre-professional training for professional football. According to the international law and democratic values that affirm the validity of the gender equality, we strive to provide conditions for the equal self-realization of boys and girls in the initial pre-professional training of young football players in accordance with their individual potential, and do not limit their development and improvement by traditional gender stereotypes.

In result of long-term research, we have justified the gender-based way in the innovative system of initial preprofessional training of boys and girls. It provides for their joint training in football from 6-8 years [5], from 9 to 12 years. Further deepening of young football players pre-professional training is carried out taking into account the interests of girls-to continue training as part of youth teams or to conduct friendly games in full or mixed teams.

\footnotetext{
${ }^{*}$ Corresponding author: suchilin.anatolij@yandex.ru
} 
We have developed a special Program for the initial pre-professional training of young football players - from 6 to 12 years based on gender equality. It provides for the formation of accessible motor skills both for boys and girls and their mutual enrichment in the development of technical and tactical techniques.

\section{Materials and methods}

The women's European football championship has been held since the mid-80s, and the list of its winners is mainly occupied by the only team - the German national team. German women have won the last 6 tournaments, with a total 8 wins. They have the title of European champion for 20 years. Traditionally the Scandinavian teams, as well as the teams of England and Italy, are the main competitors for German team during the European championship.

In the women's world Cup, since 2003, in which 24 teams participate today, the main dispute for the championship is between the United States and Germany. The most successful is the US national team. It won three of the seven Championships. The Norway, Sweden, Brazil, and China teams are also the leaders. Over 30 million women worldwide (FIFA) play football nowadays, and 14\% of them are young girls.

When Russian respondents (women and men) hear the phrase "women's football", unfortunately, they do not know much about it. Men who know about women's football in Russia are more likely to disapprove of it because of the strong pressure of gender stereotypes. At the same time, they don't openly express their negative attitude to avoid looking as a chauvinist or sexist. In Russia, women's football is still poorly developed and less popular than in Europe or in the world. Despite this, Russia began to hold a separate championship for women after 1991.

In Russia, more than 30 thousand girls and women play football but there are only about 200 professional players in 80 clubs ("women's football development Program - 2020" of the Russian Sports Federation). The main reason for the women's football lack of development is the science-based training system absence that allows women, as well as men, to prepare for professional activities.

Traditional masculinity and femininity do not meet the modern football requirements, as they limit the young athletes' potential due to gender. Despite the fact that the realization of equal rights and equal opportunities of modern men and women in sport, particularly in football, seems to be positive trend in the world. But in real Russian sports life it is hard to achieve because of the strong pressure of traditional gender stereotypes for centuries: "A diversity of views on communication between men and women in the work place has been established over centuries (it was started as an idea of a destiny to carry out different jobs by men and women, so a gender-related labor division into male and female jobs)» [6]. Researchers rightly point out that today the gender perceptions of young people intersperse traditional and egalitarian views on the ideals of gender relations due to the lack of genderbased way implementation in the initial pre-professional training of young football players (boys and girls) as a reserve for professional football. The purpose of it is to deconstruct traditional cultural restrictions that prevent the development of young football players personal potential. It should not depend on their gender; boys and girls should have the opportunity to maximize their self-realization, disclosure and development of their individual abilities in football.

Gender theory in sports (A. L. Vorozhbitova, L. I. Stolyarchuk, A. A. Suchilin, etc.), developed in the context of the social constructivist (humanitarian) paradigm, denies the relationship between the anatomy of men and women and their social "purpose" in choosing sports as a type of professional activity. In accordance with its main theoretical and methodological provisions, the biological characteristics of each gender are not the basis for social gender inequality. The hierarchical, domineering system of sexual differences is excluded. Students of both sexes are passionately trained in football. That is based on their inclinations, desires, individual abilities and life circumstances, while forming universal professional and personal qualities and skills, rather than the traditional "male" and "female". The works of sociologist Anthony Giddens[7] and the questionnaire of psychologist Sandra Boehm [8] have excluded aggressive normativism, that has given the way to the idea of masculine-feminine (androgynous) properties variability in the study of gender characteristics as variable. They are striking examples of eliminating gender discriminatory practices, both for women and men in the choice of professional activities.

The innovative gender-based way in sports, in contrast to the traditional gender-differentiated one that explores biological differences between sexes (in biological - evolutionary paradigm), considers gender as a socio-cultural gender, a socio-cultural construct created by society, changing along with the development of society (a socioconstructivist paradigm). Gender is formed in the process of socialization of the individual - the person`s development in interaction with the world around him, in professional activities, in sports, as the implementation of the gender equality idea.

The gender-based way is about changing traditional ideas of the women's status in society and sports, increasing their participation in sports activities. It is based on the individual potential of young football players. It creates prerequisites for overcoming gender inequality in sports. The gender-based way is aimed at liberalizing gender relations (liberalization, flexibility, tolerance, representation of new masculinity and femininity), it's not devoid of this specificity, but enriched with new opportunities that will allow both men and women to achieve success in football.

The gender-based way in the system of initial pre-professional training of young football players involves a partner model of gender relations based on the ideas of dialogue, tolerance, and cooperation. It does not deny the anatomical and physiological characteristics of boys and girls. It creates conditions for expanding the range of 
athletes in the development of personal universal qualities necessary for sports achievements in football, important for both men and women.

In some countries (Sweden, the Netherlands, Germany, etc.) up to 13, boys and girls form mixed teams to play in the competitions. Bert van Lingen, Dutch football coach of the Netherlands women's national team and men's youth football teams, who has worked with the national teams of the Netherlands, Belgium, Russia and Serbia, is a strong advocate of the joint initial boys and girls training in football [9]. External differences between boys and girls, according to FIFA, are not fundamental factors in the development policy of youth football.

Research methods were used: analysis of scientific and methodological literature, pedagogical observations, pedagogical experiment, interview, questionnaire survey, system analysis, gender analysis.

\section{Results and discussion}

Our rich experience, research data (A. A. Suchilin, 1996; A. p. Zolotarev, 2000; A. A. Suchilin, A. P. Zolotarev, 2004; A. A. Suchilin and L. I. Stolyarchuk, 2016, 2017, 2018, 2019, etc.)and the application of systematic and gender-based way allow us to present the system of initial pre-professional training of the football reserve, including the following 3 subsystems: preliminary training (age 6-8 years), initial training (8-10 years), initial specialization (10-12 years).

All subsystems are connected to each other. But each of them has its own specifics and can function if there are 5 mandatory elements, such as goal setting, selection (recruitment) of players, the training process, competitions and factors that complete training and competitions and optimize their effect, material support, coaching staff.

Goal setting determines the main directions of young football players training. In each of the subsystems it has its own characteristics:

In preliminary training subsystem (6-8 years), special attention is paid to health promotion, cultivating interest for classes, mastering the available elements of the football game, developing coordination and speed qualities. Due to the lack of differences in age characteristics, it is advisable to conduct pre-professional training of boys and girls together. Mobile games ("Empty Space", "at the Bear on the Forest", "Do not give the Ball", etc.), sports games (relay races, basketball, handball according to simplified rules, etc.), games with elements of football (1x1, $2 \times 1,2 \times 2)$, exercises in hitting and stopping the ball, etc.

In initial training subsystem (8-10 years), - there is an education of discipline and perseverance in mastering the available technical and tactical techniques. As a means, passing and driving the ball, deceptive movements and ball selections exercises are used. Individual peculiarities of performing motor actions, their preservation and development are revealed. Technical and tactical actions are mastered on small playgrounds in limited formations of $3 \times 3,4 \times 4,5 \times 5$. Joint training of boys and girls continues.

In initial specialization subsystem (10-12 years) - continue to master the basic techniques, their use in game conditions, develop coordination abilities, speed and strength qualities. There is an education of strong-willed qualities: perseverance, determination and courage, endurance and self-control. Team play in limited $6 \times 6$ teams on the half of the football field is mastered.

The rise of professional football to a higher quality level requires reserve players to increase the parameters, volume and intensity of actions, and coaches to organize classes using innovative technologies aimed at improving speed and strength qualities, speed endurance, mastering complex techniques and skills. In fact, you should use a wide range of simulators, ergogenic, hygienic and other non-traditional means to improve the training process efficiency.

The gender-based way necessity in the development of a modern reserve training system is proved because the previous system was built in the Soviet Union and was based on the Communist ideology, when children were first pioneers, then Komsomol members. Most of them were obedient boys who did not need to be persuaded to train hard. The obedience and attainment in studies were educated by parents, school, pioneer and Komsomol organizations.

The formation and development of pre-professional reserve training modern innovative system for professional football takes place in different conditions, when there is no ideological pressure, and traditional gender stereotypes are gradually eliminated.

Pedagogical observations and research results also show that physical development and physical fitness of professional football players have changed significantly over the past decade. The raised number of single combats on the football field, the increase in the pace of play and high-speed movements required the selection of players with high physical conditions, high-speed qualities and quick decision-making in difficult game situations. The higher height and weight dimensions of the team's players on the Central axis were clearly defined: the goalkeeper, Central defenders, defensive Midfielders, and Central forwards. Their height and weight characteristics are not inferior to handball players, basketball players and water Polo players. The selection of players by playing roles during the initial pre-professional training as a sports reserve in football gets particular importance.

Innovative system of initial pre-service training, reflecting the current stage of professional football development needs to implement a systemic and gender -based way. On the one hand, it opens up more opportunities for young players (girls and boys), and on the other hand, it develops their stress tolerance, since changing anthropometric characteristics of football players may not correspond to a qualitatively new level of football development over time. 


\section{Conclusions}

The high level of professional football development testifies to the wide participation of women in various ranks competitions: national Championships, European and world Championships, Olympic games.

The gender-based way, based on an egalitarian strategy, asserts a partner model of equal relationships. That does not deny the anatomical and physiological characteristics of boys and girls but focuses on the social aspect of gender, creates conditions for the development of individual professional and personal qualities of young athletes. They are important while choosing football as a professional activity.

Initial pre-professional training of young football players is a long-term educational and training process. It can be represented as a complex system that includes 3 subsystems: - preliminary training (age 6-8 years), initial training (8-10 years), initial specialization (10-12 years).

The initial pre-professional training of young football players-boys and girls from 6 to 12 years old-is conducted in the same groups, since their age characteristics do not have significant differences and create the necessary prerequisites for organizing classes using the same methodology.

Further in-depth pre-professional training of young football players-boys and girls aged 13-20 years will cover the subsystem of in-depth sports specialization improvement and skill. At the same time, boys and girls will be engaged in separate groups, but also if they want to improve their skills in friendly, control and other unofficial games, since professional modern football is divided into women's and men's. However, the modern system of initial pre-professional young football players training in gender-based way (boys and girls) is more appropriate. As it promotes mutual enrichment in the development of technical and tactical techniques, allows overcoming gender inequality in sports, allows women to play football on an equal basis with men. As it was traditionally considered only a "male" sport, and subsequently achieve great success in professional football.

\section{References}

1. A.P. Laptev, A.A. Suchilin. Young football player (Physical culture and Sport, Moscow, 1983)

2. Football. Program for children's and youth sports schools and specialized children's and youth schools of the Olympic reserve (Physical culture and sports, Moscow, 1977)

3. A.A. Suchilin, I.N. Novokshchenov, The Russian Journal of Physical Education and Sport, 13(1), 46-52 (2018)

4. A.A. Suchilin, Preparation of the Olympic reserve in football (Print, Volgograd, 2017)

5. A.A. Suchilin, First international Volga region conference on Economics, Humanities and Sports (tickets 19) (Atlantis press, $114,2019)$

6. L.I. Stolyarchuk, IOP conf. Serial.: Mama. Sci. Eng. 483012063 BTCI 2018 IOP Conf. Series: 48483 (2019) 2018 btci 012063 IOP Publishing doi: 10.1088 / 1757-899x/483/1/012063

7. Giddens, Sociology (6-pol Polity Press, 1183, 2009)

8. S.L. Bem, 1981 bem sex role inventory professional manual (Consulting Psychologists Press)

9. Advocaat targets Dutchman van Lingen as Ibrox's No. 2 IB 